\title{
A Novel Human Opsin in the Inner Retina
}

\author{
Ignacio Provencio, ${ }^{1}$ Ignacio R. Rodriguez, ${ }^{2}$ Guisen Jiang, ${ }^{1}$ William Pär Hayes, ${ }^{3}$ Ernesto F. Moreira, ${ }^{2}$ and \\ Mark D. Rollag ${ }^{1}$ \\ ${ }^{1}$ Department of Anatomy and Cell Biology, Uniformed Services University of the Health Sciences, Bethesda, Maryland \\ 20814, ${ }^{2}$ National Eye Institute, National Institutes of Health, Bethesda, Maryland 20892, and ${ }^{3}$ Department of Biology, The \\ Catholic University of America, Washington, DC 20064
}

\begin{abstract}
Here we report the identification of a novel human opsin, melanopsin, that is expressed in cells of the mammalian inner retina. The human melanopsin gene consists of 10 exons and is mapped to chromosome 10q22. This chromosomal localization and gene structure differs significantly from that of other human opsins that typically have four to seven exons. A survey of 26 anatomical sites indicates that, in humans, melanopsin is expressed only in the eye. In situ hybridization histochemistry shows that melanopsin expression is restricted to cells within the ganglion and amacrine cell layers of the primate and murine retinas. Notably, expression is not observed in retinal photore-
\end{abstract}

ceptor cells, the opsin-containing cells of the outer retina that initiate vision. The unique inner retinal localization of melanopsin suggests that it is not involved in image formation but rather may mediate nonvisual photoreceptive tasks, such as the regulation of circadian rhythms and the acute suppression of pineal melatonin. The anatomical distribution of melanopsinpositive retinal cells is similar to the pattern of cells known to project from the retina to the suprachiasmatic nuclei of the hypothalamus, a primary circadian pacemaker.

Key words: circadian; melanopsin; opsin; photoreceptor; retina; retinal ganglion cell
Light is a potent regulator of many physiological processes in vertebrates. For example, the synchronization of circadian rhythms to the $24 \mathrm{hr}$ solar cycle and the proper seasonal timing of reproduction are greatly influenced by environmental light cues. Among nonmammalian vertebrates, many of these processes persist in the absence of eyes (Groos, 1982). This finding indicates that some effects of light are mediated through extraocular photoreceptors. Several extraocular tissues in nonmammalian vertebrates have been shown to be directly photosensitive in culture. These include the pineal gland (Deguchi, 1979), the iris (Barr and Alpern, 1963), and dermal melanophores (Seldenrijk et al., 1979). Within the past 5 years, multiple novel opsins have been identified and localized to extraocular sites in nonmammalian vertebrates. Pinopsin is found in the pineal gland of birds (Okano et al., 1994; Max et al., 1995; Kawamura and Yokoyama, 1996) and reptiles (Kawamura and Yokoyama, 1997) and in the brain of toads (Yoshikawa et al., 1998). Parapinopsin is present in the parapineal gland of the catfish (Blackshaw and Snyder, 1999). Melanopsin is localized to various extraretinal tissues in amphibians, including dermal melanophores, deep brain nuclei, and iris (Provencio et al., 1998b). Melanopsin and vertebrate ancient opsin have also been observed in nonphotoreceptor cells of the inner retina of frogs and fish, respectively (Provencio et al., 1998b; Soni et al., 1998).

Mammals also detect light for the entrainment of circadian rhythms and the regulation of pineal melatonin production. In contrast to nonmammalian vertebrates, the photoreceptors medi-

\footnotetext{
Received Aug. 16, 1999; revised Nov. 2, 1999; accepted Nov. 4, 1999.

This work was supported by National Science Foundation Grant IBN-9809916 and Uniformed Services University of the Health Sciences Grant RO7049 (both to M.D.R.). We thank Dr. Paul Russell for the monkey eye tissue, Dr. Diane Borst for the mouse tissue, and Dr. Michael Flora for helpful discussions.

Correspondence should be addressed to Mark D. Rollag, Department of Anatomy, Uniformed Services University of the Health Sciences, 4301 Jones Bridge Road, Bethesda, MD 20814. E-mail: mrollag@usuhs.mil.

Copyright (C) 2000 Society for Neuroscience 0270-6474/00/200600-06\$15.00/0
}

ating nonvisual photic processes are ocular in mammals (Nelson and Zucker, 1981). However, the rod and cone photoreceptors of the retina are not required for the regulation of circadian rhythms or acute suppression of pineal melatonin levels (Freedman et al., 1999; Lucas et al., 1999). The ocular photoreceptors mediating these nonvisual tasks in mammals remain unknown. Having localized melanopsin to amphibian tissues known to contain extraretinal photoreceptors and to nonphotoreceptor cells of the amphibian retina (Provencio et al., 1998b), we hypothesize that melanopsin expression can be used as a tool to identify candidate nonvisual photoreceptors in other vertebrates, including mammals.

\section{MATERIALS AND METHODS}

Cloning of human melanopsin. A lambda human genomic DNA library (Clontech, Palo Alto, CA) was screened with a 475 bp oligonucleotide probe derived from the chicken melanopsin cDNA sequence (M. D. Rollag, I. Provencio, and M. Zatz, unpublished data). DNA from a positive partial clone was restriction mapped, subcloned into pGEM3Zf $(+)$ (Promega, Madison, WI), and sequenced (PE Biosystems, Foster City, CA). A genespecific primer pair was derived from the sequence of the partial genomic clone (primer IPF85, 5'-GGAGGAGAGAAGGCACACAG-3'; primer IPB83, 5'-GCTGCTGCAG-ATGTCACAAT-3'). These primers were used to screen for a Genome Systems (St. Louis, MO) PAC clone (number 20775) containing the entire melanopsin gene. The Coriell Monochromosomal Panel 2 (Coriell Cell Repositories, Camden, NJ) was PCR screened with primers IPF85 and IPB83 to establish a gross chromosomal localization. A finer localization was achieved by a PCR screen with the same primers against the Stanford Human Genome Center G3 radiation hybrid panel (Stewart et al., 1997). PCR primers were also designed within putative coding regions of the genomic sequence as determined by homology to Xenopus melanopsin (primer IPF70, 5'-GACACCCTACATGAGCTCGG-3'; primer IPB64, 5'-CTGTACTTGGGGTGGGTGAT-3'). These primers were used to amplify a $95 \mathrm{bp}$ melanopsin cDNA fragment by PCR (PE Biosystems) from human retina cDNA. A full-length cDNA was obtained by $5^{\prime}$ and $3^{\prime}$ rapid amplification of cDNA ends (RACE) (Life Technologies, Rockville, MD).

Reverse transcription-PCR of multiple tissues. Human total RNA was obtained (Clontech) or isolated from tissues (National Disease Research 


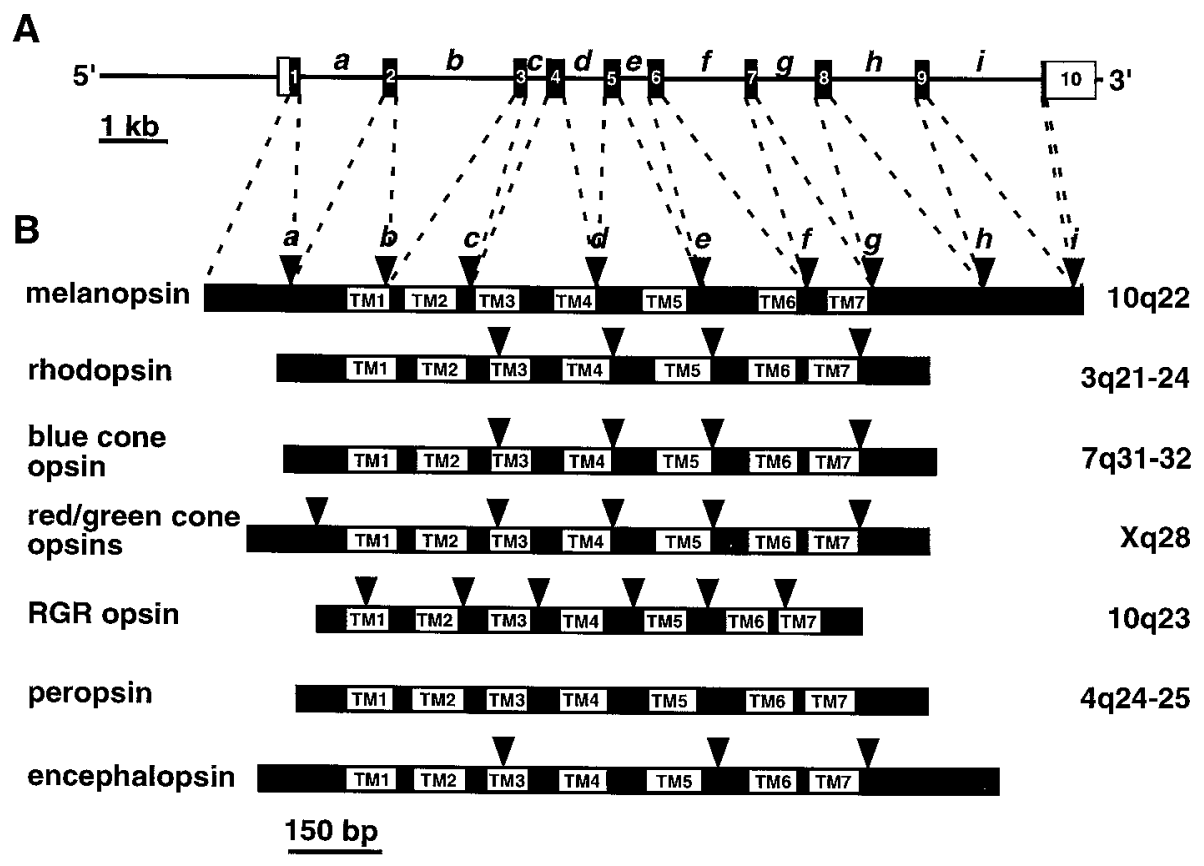

Figure 1. Melanopsin differs from other human opsins. A, Structure of melanopsin gene. The $5^{\prime}$ and $3^{\prime}$ untranslated regions of exons 1 and 10 , respectively, are indicated in white. $B$, Comparison of human melanopsin, rhodopsin (Nathans and Hogness, 1984), blue cone opsin (Nathans et al., 1986), red and green cone opsins (Nathans et al., 1986), RGR (Shen et al., 1994), peropsin (Hui et al., 1997), and encephalopsin (Blackshaw and Snyder, 1999) ORFs. Portions of the ORFs corresponding to the transmembrane domains are shown in white and are labeled. Positions of introns are indicated ( $\mathbf{\nabla})$, and the respective chromosomal locations are displayed to the right.

Interchange, Philadelphia, PA) by the guanidinium thiocyanate method (Chomczynski and Sacchi, 1987) and reverse transcribed onto magnetic beads as described previously (Rodriguez et al., 1994). One microliter of solid phase cDNA from each tissue was subjected to PCR amplification (AmpliTaq Gold polymerase; PE Biosystems) for 20 cycles using human glyceraldehyde-3-phosphate dehydrogenase (GAPDH)-specific primers (primer GAPDH forward, 5'-CCACCCATGGCAAATTCCATGGCA-3'; primer GAPDH reverse, 5'-TCTAGACGGCAGGTCAGGTCCACC-3') or 30 cycles using human melanopsin-specific primers (primer IPF108, 5'-ACTCAGGATGAACCCTCCTTC-3'; primer IPB91, 5'-TGAACATGTTGGCAGGTGTC- $3^{\prime}$ ). The GAPDH and melanopsin PCR reactions from each tissue were mixed $1: 1(\mathrm{v} / \mathrm{v})$, and $5 \mu \mathrm{l}$ of each mixture was electrophoresed and visualized by ethidium bromide staining. The expected products for the melanopsin and GAPDH primer pairs from cDNA template are 334 and $600 \mathrm{bp}$, respectively. The expected products for the melanopsin and GAPDH primer pairs from genomic DNA template are 3292 and 1104 bp, respectively.

Cloning of mouse melanopsin. A 228 bp mouse (Mus musculus) melanopsin cDNA fragment was PCR-amplified (AmpliTaq Gold polymerase; PE Biosystems) from mouse retina cDNA using human melanopsin-specific primers (primer IPF82, 5'-ATCCTGCTCCTGGGACTACA-3'; primer IPB74, 5'-ATCTTGGCCATCTTGCACTC-3'). A full-length cDNA was subsequently obtained by $5^{\prime}$ and $3^{\prime}$ RACE (Life Technologies).

In situ hybridization histochemistry. Adult macaque (Macaca mulatta) and adult and juvenile (postnatal day 10) mouse eyes were removed. The corneas and lenses were dissected away from the adult eyes. The resulting tissues were either immersion fixed (4\% formalin, $24 \mathrm{hr}$ ), frozen in TissueTek (Miles, Elkhart, IN) and immediately freeze-mounted, or placed into TRI-reagent (Sigma, St. Louis, MO) for RNA isolation. Total RNA was isolated by the guanidinium thiocyanate method (Chomczynski and Sacchi, 1987). A $417 \mathrm{bp}$ cDNA fragment of the macaque melanopsin homolog was obtained by reverse transcription (RT)-PCR using primers designed from the human melanopsin cDNA sequence (primer IPF82, 5'-ATCCTGCTCCTGGGACTACA-3'; primer IPB64, 5'-CTGTACTTGGGGTGGGTGAT-3'). Products were cloned into pCRII-TOPO (Invitrogen, Carlsbad, CA) and sequenced. A 957 bp mouse melanopsin cDNA fragment was similarly cloned using mouse melanopsin-specific primers (primer IPF107, 5'-TCTTCATCTTCAGGGCCATC-3'; primer IPB116, 5'-TTCTCTGCTGTAGGCCACATA-3'). Plasmids were used to generate ${ }^{35}$ S-labeled antisense and sense control riboprobes (Ambion, Austin, TX). Eyecups were sectioned $(15 \mu \mathrm{m})$, thaw-mounted onto silanized RNase-free microscope slides, and hybridized with the riboprobes as described previously (Shi and Hayes, 1994).

\section{RESULTS}

\section{Cloning of human melanopsin}

We determined the nucleotide sequence of both strands of the human melanopsin gene, including exons, introns, and $2.6 \mathrm{~kb}$ of the 5' flanking region (GenBank accession number AF147788). All introns are flanked by consensus splice sites. The melanopsin gene has 10 exons distributed over $11.8 \mathrm{~kb}$. Its gene structure is unique among the vertebrate opsins as evidenced by intron positions significantly different from the intron positions of the rod and cone opsins (Fig. 1). PCR screens of the radiation hybrid panels mapped the melanopsin gene to human chromosome 10q22. A $2.3 \mathrm{~kb}$ melanopsin cDNA containing a $1.4 \mathrm{~kb}$ open reading frame $(\mathrm{ORF})$ was cloned from human retina cDNA, indicating that melanopsin is normally transcribed in the human eye. RT-PCR from 26 human anatomical sites demonstrated melanopsin expression in the eyes but in none of the other sites examined (Fig. 2). Unlike Xenopus, human melanopsin expression was not observed in the pineal gland or any brain region examined.

\section{Cloning of mouse melanopsin}

We cloned a $2.1 \mathrm{~kb}$ melanopsin cDNA with a $1.6 \mathrm{~kb}$ open reading frame from mouse retina cDNA (GenBank accession number AF147789). When the human and mouse cDNAs are translated and aligned, the predicted transmembrane and loop domains are $86 \%$ identical to each other (Fig. 3) and 57\% identical to the frog homolog. The cytoplasmic and extracellular tails are significantly different in sequence and length. 


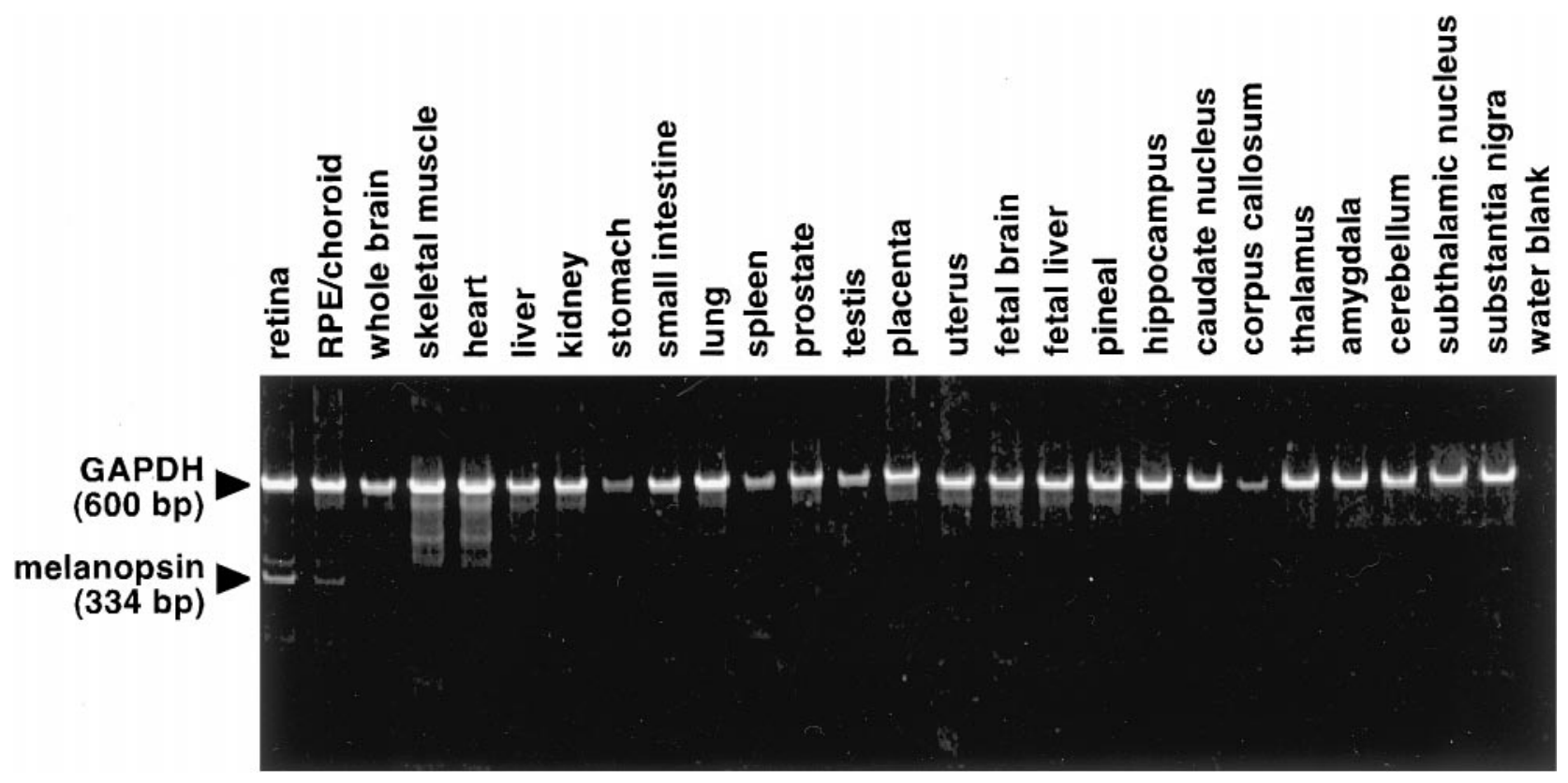

Figure 2. Human melanopsin is expressed in the eye. RT-PCR from multiple human tissues of melanopsin (334 bp) and the GAPDH positive control $(600 \mathrm{bp})$. The faint melanopsin product from RPE/choroid may have resulted from retinal contamination during dissection. Melanopsin is not expressed in the other tissues examined.

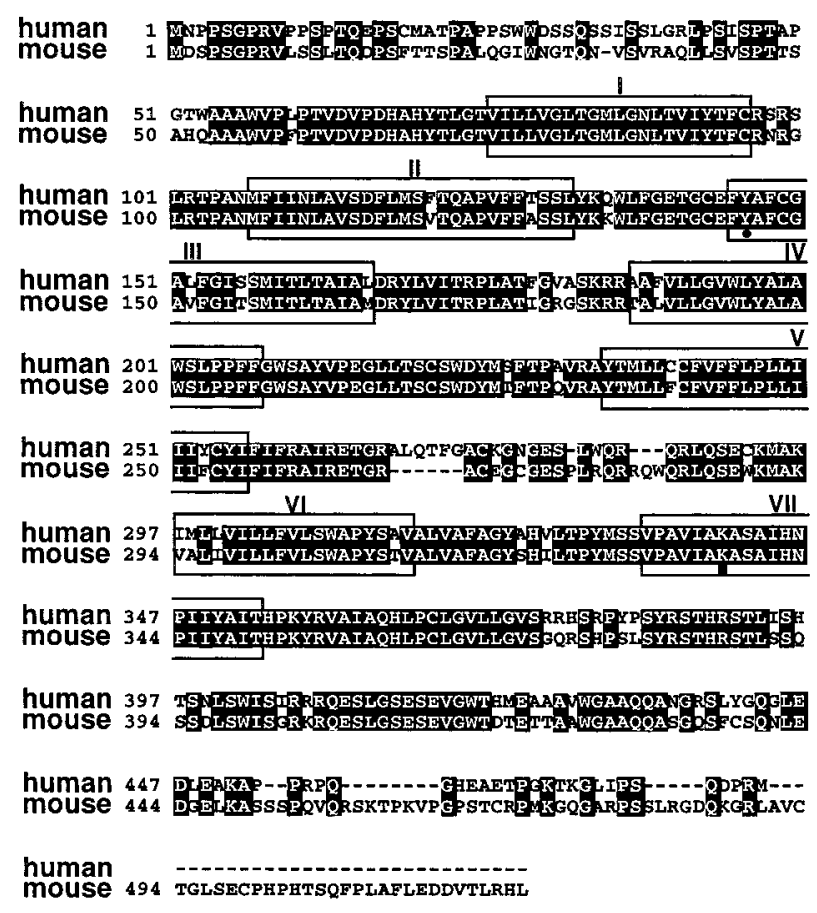

Figure 3. Alignment of human and mouse melanopsin-deduced amino acid sequences. Sequences were aligned with ClustalW 1.6 (Thompson et al., 1994). Predicted transmembrane domains are boxed and were determined by homology to Xenopus melanopsin (Provencio et al., 1998b). The

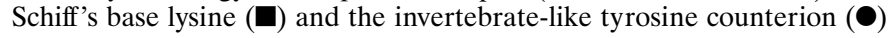
are indicated.

\section{In situ hybridization histochemistry}

In primates, a low level of melanopsin expression is observed in many retinal cells within the ganglion cell layer of the retina (Fig. 4). Higher levels of message are found in sparsely distributed cells within the inner lamina of the inner nuclear layer among ama-
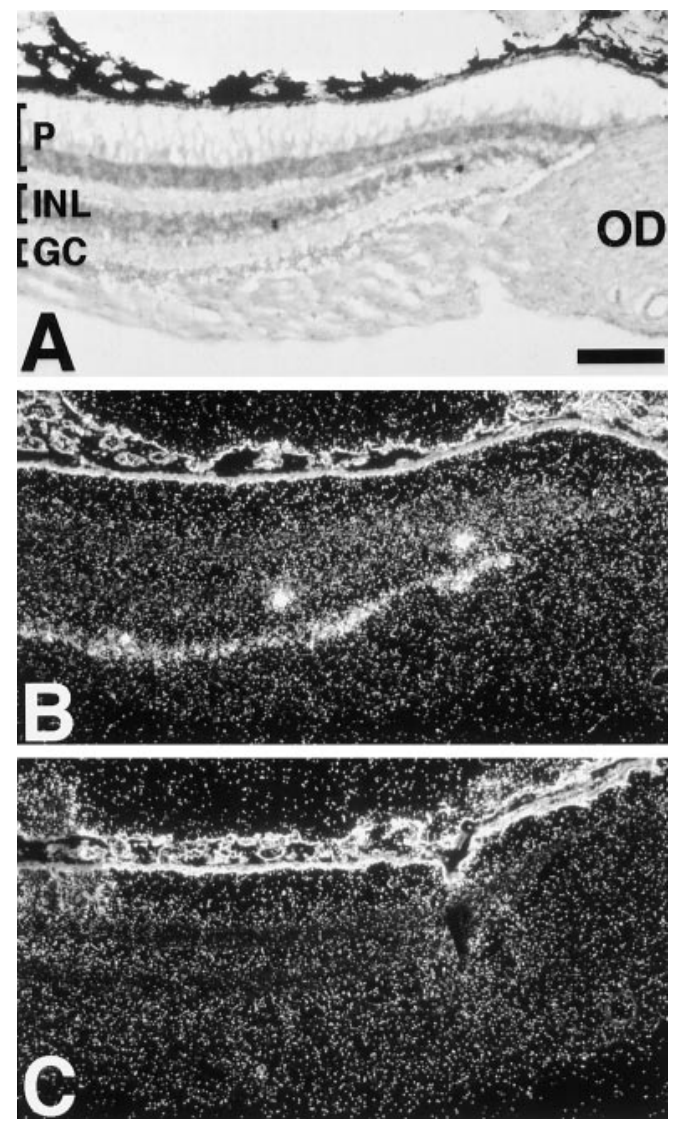

Figure 4. Melanopsin is expressed in the monkey inner retina. Brightfield $(A)$ and dark-field $(B)$ photomicrographs of a section of monkey retina probed with an antisense monkey melanopsin riboprobe. $C$, An adjacent section probed with a sense control riboprobe. $G C$, Ganglion cell layer; $I N L$, inner nuclear layer; $O D$, optic disk; $P$, photoreceptor layer. Scale bar, $150 \mu \mathrm{m}$. 


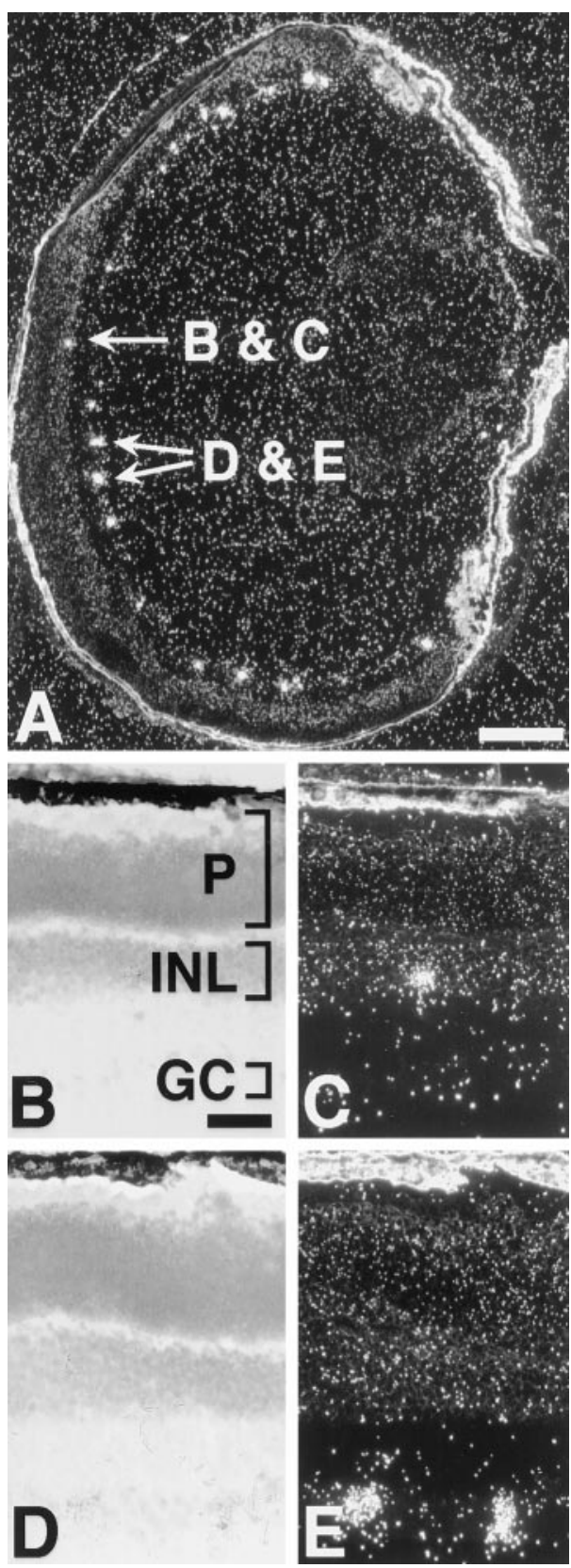

Figure 5. Melanopsin is expressed in the mouse inner retina. $A$, Crosssection of a 10-d-old mouse eye probed with an antisense mouse melanopsin riboprobe. $B, C$, Bright-field and dark-field photomicrographs of indicated cell within the amacrine cell layer in $A . D, E$, Bright-field and dark-field photomicrographs of indicated cell pair within the ganglion cell layer in $A$. $G C$, Ganglion cell layer; $I N L$, inner nuclear layer; $P$, photoreceptor layer. Scale bars: $A, 250 \mu \mathrm{m} ; B, 50 \mu \mathrm{m}$.

crine cell perikarya. In the mouse retina, melanopsin is expressed in only a few cells in the ganglion cell layer and even fewer cells in the amacrine cell layer (Fig. 5).

\section{DISCUSSION}

Perhaps the most striking feature that distinguishes melanopsin from other human opsins is its greater sequence homology with the invertebrate opsins than those of vertebrates. In fact, the predicted amino acid sequence is more similar to the $\mathrm{G}_{\mathrm{q}}$-coupled opsin of the scallop (Kojima et al., 1997) than to any known vertebrate opsin. The similarity to the invertebrate photopigments is also apparent in several predicted structural and biochemical features. This includes the substitution of the acidic Schiff's base "counterion," typical of vertebrate opsins, with an aromatic residue that is typical of the invertebrate opsins. The absence of this acidic counterion in melanopsin suggests that the photopigment-regenerating mechanism more closely resembles that of the invertebrates (Gärtner and Towner, 1995). Invertebrate opsin-based photopigments retain their retinaldehyde chromophore after it is photoisomerized from the 11-cis to all-trans configuration. The retained chromophore is reisomerized to the 11-cis configuration by a second wavelength of light. This in situ photopigment regeneration does not require proximity to an auxiliary chromophore-regenerating tissue, such as the retinal pigment epithelium (RPE). Such anatomical independence is a valuable attribute for nonvisual photoreceptors that may reside in a wide variety of tissues. Indeed, cells containing melanopsin transcripts in the retina are not juxtaposed to the RPE but rather are situated within neural elements of the inner retina.

The inner retinal distribution of melanopsin-positive cells shares a remarkable resemblance to the cohort of retinal cells known to project to the primary circadian pacemaker of rodents, the suprachiasmatic nuclei (SCN) of the hypothalamus (Pickard, 1980, 1982; Moore et al., 1995). In mice, only a small subset of widely distributed retinal ganglion and amacrine-like cells project to the SCN (Balkema and Dräger, 1990; Provencio et al., 1998a). The number and location of these cells are similar to that of the melanopsin-positive cells.

The presence of melanopsin in the inner retina raises the possibility that some mammalian ganglion and amacrine cells are directly photosensitive. This possibility is consistent with the finding that naturally occurring and transgenic mice that lack rods and cones, although maintaining an apparently normal inner retina, are capable of photoregulating circadian locomotor activity rhythms and pineal melatonin levels in a manner indistinguishable from wild-type controls (Foster et al., 1991; Provencio et al., 1994; Freedman et al., 1999). Bilateral removal of the eyes abolishes such regulation (Nelson and Zucker, 1981). Together, these data indicate that, whereas the eyes are required for the effect of light on the circadian axis, the visual photoreceptors are not necessary. This paradox strongly suggests that some class of nonrod, noncone photoreceptor exists within the mammalian eye. Ocular nonvisual photoreception would explain why some humans retain an ability to acutely suppress serum melatonin concentrations in response to light exposure despite being cognitively and clinically blind (Czeisler et al., 1995).

The prospect that retinal ganglion cells are photoreceptive has received much attention because of the discovery that many mouse ganglion cells contain cryptochromes, a class of blue light-absorbing, flavin-based photopigments related to DNA photolyases (Miyamoto and Sancar, 1998). Two cryptochromes (mCRY1 and mCRY2) have been localized to ganglion and inner nuclear cells and have been proposed as candidate circadian photopigments. Knock-out mice missing one or both cryptochromes have been constructed to assess their role in circadian rhythm regulation (Thresher et al., 1998; van der Horst et al., 1999). One would expect the phenotype of a circadian photopigment-deficient mouse to be like that of a bilaterally enucleated mouse (Nelson and Zucker, 1981). That is to say, a mouse incapable of circadian photoreception should be unable to entrain its circadian locomotor activity rhythms to the light/dark cycle. Instead, it has been found that mice lacking either of the 
cryptochromes remain capable of photoentrainment (Thresher et al., 1998; van der Horst et al., 1999; Vitaterna et al., 1999). Mice missing both cryptochromes are arrhythmic, probably as a result of a nonf unctioning clock. This latter finding makes the analysis of entrainment in cryptochrome double knock-out mice difficult. Thus, the issue of whether mice lacking both cryptochromes can photoentrain remains unresolved (van der Horst et al., 1999; Vitaterna et al., 1999). Together, these data from knock-out mice fail to show that cryptochromes act as circadian photopigments. Rather, they suggest that cryptochromes are critical components of the molecular machinery of the clock. This conclusion has been strengthened by investigators who have shown that cryptochromes are indeed essential components of the mammalian circadian clock (Griffin et al., 1999; Kume et al., 1999). Furthermore, there is evidence that the functional interaction of mammalian cryptochromes with other clock proteins is independent of light, again strongly suggesting that cryptochromes are not acting as circadian photopigments within the circadian system of mammals (Griffin et al., 1999).

An independent method to discriminate whether flavin- or opsin-based photopigments mediate particular light responses is through action spectrum analysis (Lucas and Foster, 1999). Action spectra of rodent circadian responses more closely resemble the spectral absorbance profile of opsin-based photopigments rather than flavin-based cryptochromes (Takahashi et al., 1984; Provencio and Foster, 1995; Yoshimura and Ebihara, 1996). Melanopsin is one of four opsins expressed outside the photoreceptor layer in human and mouse retinas, the other three being retinal G-protein-coupled receptor (RGR), peropsin, and encephalopsin. RGR is found predominantly in intracellular membranes of the RPE and Müller cells (Pandey et al., 1994) and functions as a photoisomerase (Hao and Fong, 1999). Peropsin is found within the microvilli of RPE cells, and its function is unknown (Hui et al., 1997). The function of encephalopsin is also unknown, and it has not yet been shown to be expressed in the eye (Blackshaw and Snyder, 1999). Melanopsin is the only one of the four known mammalian nonvisual opsins that is expressed by cells in the ganglion and amacrine cell layers of the retina. This unique anatomical localization, coupled with the known action spectra for mammalian circadian photoregulation, makes melanopsin a viable candidate as a mammalian circadian photopigment.

\section{REFERENCES}

Balkema GW, Dräger UC (1990) Origins of uncrossed retinofugal projections in normal and hypopigmented mice. Vis Neurosci 4:595-604.

Barr L, Alpern M (1963) Photosensitivity of the frog iris. J Gen Physiol 46:1249-1265.

Blackshaw S, Snyder SH (1999) Encephalopsin: a novel mammalian extraretinal opsin discretely localized in the brain. J Neurosci 19:3681-3690.

Chomczynski P, Sacchi N (1987) Single-step method of RNA isolation by acid guanidinium thiocyanate-phenol-chloroform extraction. Anal Biochem 162:156-159.

Czeisler CA, Shanahan TL, Klerman EB, Martens H, Brotman DJ, Emens JS, Klein T, Rizzo JD (1995) Suppression of melatonin secretion in some blind patients by exposure to bright light. N Engl J Med 332:6-11.

Deguchi T (1979) A circadian oscillator in cultured cells of chicken pineal gland. Nature 282:94-96.

Foster RG, Provencio I, Hudson D, Fiske S, De Grip W, Menaker M (1991) Circadian photoreception in the retinally degenerate mouse $(r d / r d)$. J Comp Physiol [A] 169:39-50.

Freedman MS, Lucas RJ, Soni B, von Schantz M, Muñoz M, David-Gray Z, Foster R (1999) Regulation of mammalian circadian behavior by non-rod, non-cone, ocular photoreceptors. Science 284:502-504.
Gärtner W, Towner P (1995) Invertebrate visual pigments. Photochem Photobiol 62:1-16.

Griffin Jr EA, Staknis D, Weitz CJ (1999) Light-independent role of CRY1 and CRY2 in the mammalian circadian clock. Science 286:768-771.

Groos G (1982) The comparative physiology of extraocular photoreception. Experientia 38:989-1128.

Hao W, Fong HK (1999) The endogenous chromophore of retinal G protein-coupled receptor opsin from the pigment epithelium. J Biol Chem 274:6085-6090.

Hui S, Gilbert DB, Copeland NG, Jenkins NA, Nathans J (1997) Peropsin, a novel visual pigment-like protein located in the apical microvilli of the retinal pigment epithelium. Proc Natl Acad Sci USA 94:9893-9898.

Kawamura S, Yokoyama S (1996) Molecular characterization of the pigeon P-opsin gene. Gene 182:213-214.

Kawamura S, Yokoyama S (1997) Expression of visual and nonvisual opsins in American chameleon. Vision Res 37:1867-1871.

Kojima D, Terakita A, Ishikawa T, Tsukahara Y, Maeda A, Shichida Y (1997) A novel Go-mediated phototransduction cascade in scallop visual cells. J Biol Chem 272:22979-22982.

Kume K, Zylka MJ, Sriram S, Shearman LP, Weaver DR, Jin X, Maywood ES, Hastings MH, Reppert SM (1999) $m C R Y 1$ and $m C R Y 2$ are essential components of the negative limb of the circadian clock feedback loop. Cell 98:193-205.

Lucas RJ, Foster RG (1999) Photoentrainment in mammals: a role for cryptochrome? J Biol Rhythms 14:4-10.

Lucas RJ, Freedman MS, Muñoz M, Garcia-Fernandez JM, Foster RG (1999) Regulation of the mammalian pineal by non-rod, non-cone, ocular photoreceptors. Science 284:505-507.

Max M, McKinnon PJ, Seidenman KJ, Barrett RK, Applebury ML, Takahashi JS, Margolskee RF (1995) Pineal opsin: a nonvisual opsin expressed in chick pineal. Science 267:1502-1506.

Miyamoto Y, Sancar A (1998) Vitamin $B_{2}$-based blue-light photoreceptors in the retinohypothalamic tract as the photoactive pigments for setting the circadian clock in mammals. Proc Natl Acad Sci USA 95:6097-6102.

Moore RY, Speh JC, Card JP (1995) The retinohypothalamic tract originates from a distinct subset of retinal ganglion cells. J Comp Neurol 352:351-366.

Nathans J, Hogness DS (1984) Isolation and nucleotide sequence of the gene encoding human rhodopsin. Proc Natl Acad Sci USA 81:4851-4855.

Nathans J, Thomas D, Hogness DS (1986) Molecular genetics of human color vision: the genes encoding blue, green, and red pigments. Science 232:193-202.

Nelson RJ, Zucker I (1981) Absence of extraocular photoreception in diurnal and nocturnal rodents exposed to direct sunlight. Comp Biochem Physiol 69A:145-148.

Okano T, Yoshizawa T, Fukada Y (1994) Pinopsin is a chicken pineal photoreceptive molecule. Nature 372:94-97.

Pandey S, Blanks JC, Spee C, Jiang M, Fong HK (1994) Cytoplasmic retinal localization of an evolutionary homolog of the visual pigments. Exp Eye Res 58:605-613.

Pickard GE (1980) Morphological characteristics of retinal ganglion cells projecting to the suprachiasmatic nucleus: a horseradish peroxidase study. Brain Res 183:458-465.

Pickard GE (1982) The afferent connections of the suprachiasmatic nucleus of the golden hamster with emphasis on the retinohypothalamic projection. J Comp Neurol 211:65-83.

Provencio I, Foster RG (1995) Circadian rhythms in mice can be regulated by photoreceptors with cone-like characteristics. Brain Res 694:183-190.

Provencio I, Wong S, Lederman AB, Argamaso SM, Foster RG (1994) Visual and circadian responses to light in aged retinally degenerate mice. Vision Res 34:1799-1806.

Provencio I, Cooper HM, Foster RG (1998a) Retinal projections in mice with inherited retinal degeneration: Implications for circadian photoentrainment. J Comp Neurol 395:417-439.

Provencio I, Jiang G, De Grip WJ, Hayes WP, Rollag MD (1998b) Melanopsin: an opsin in melanophores, brain, and eye. Proc Natl Acad Sci USA 95:340-345.

Rodriguez IR, Mazuruk K, Schoen TJ, Chader GJ (1994) Structural analysis of the human hydroxyindole- $O$-methyltransferase gene. Presence of two distinct promoters. J Biol Chem 269:31969-31977. 
Seldenrijk R, Hup DR, de Graan PN, van de Veerdonk FC (1979) Morphological and physiological aspects of melanophores in primary culture from tadpoles of Xenopus laevis. Cell Tissue Res 198:397-409.

Shen D, Jiang M, Hao W, Tao L, Salazar M, Fong HK (1994) A human opsin-related gene that encodes a retinaldehyde-binding protein. Biochemistry 33:13117-13125.

Shi YB, Hayes WP (1994) Thyroid hormone-dependent regulation of the intestinal fatty acid-binding protein gene during amphibian metamorphosis. Dev Biol 161:48-58.

Soni BG, Philp AR, Foster RG, Knox BE (1998) Novel retinal photoreceptors. Nature 394:27-28.

Stewart EA, McKusick KB, Aggarwal A, Bajorek E, Brady S, Chu A, Fang N, Hadley D, Harris M, Hussain S, Lee R, Maratukulam A, O'Connor K, Perkins S, Piercy M, Qin F, Reif T, Sanders C, She X, Sun WL, Tabar P, Voyticky S, Cowles S, Fan JB, Cox DR, Mader C, Quackenbush J, Meyers RM (1997) An STS-based radiation hybrid map of the human genome. Genome Res 7:422-433.

Takahashi JS, DeCoursey PJ, Bauman L, Menaker M (1984) Spectral sensitivity of a novel photoreceptive system mediating entrainment of mammalian circadian rhythms. Nature 308:186-188.

Thompson JD, Higgins DG, Gibson TJ (1994) CLUSTAL W: improving the sensitivity of progressive multiple sequence alignment through sequence weighting, position-specific gap penalties and weight matrix choice. Nucleic Acids Res 22:4673-4680.

Thresher RJ, Vitaterna MH, Miyamoto Y, Kazantsev A, Hsu DS, Petit C, Selby CP, Dawut L, Smithies O, Takahashi JS, Sancar A (1998) Role of mouse cryptochrome blue-light photoreceptor in circadian photoresponses. Science 282:1490-1494.

van der Horst GTJ, Miujtjens M, Kobayashi K, Takano R, Kanno S, Takao M, de Wit J, Verkerk A, Eker APM, van Leenen D, Buijs R, Bootsma D, Hoeijmakers JHJ, Yasui A (1999) Mammalian Cry1 and Cry2 are essential for maintenance of circadian rhythms. Nature 398:627-630.

Vitaterna MH, Selby CP, Todo T, Niwa H, Thompson C, Fruechte EM, Hitomi K, Thresher RJ, Ishikawa T, Miyazaki J, Takahashi JS, Sancar A (1999) Differential regulation of mammalian period genes and circadian rhythmicity by cryptochromes 1 and 2. Proc Natl Acad Sci USA 96:12114-12119.

Yoshikawa T, Okano T, Oishi T, Fukada Y (1998) A deep brain photoreceptive molecule in the toad hypothalamus. FEBS Lett 424:69-72.

Yoshimura T, Ebihara S (1996) Spectral sensitivity of photoreceptors mediating phase-shifts of circadian rhythms in retinally degenerate $\mathrm{CBA} / \mathrm{J}(\mathrm{rd} / \mathrm{rd})$ and normal CBA/N $(+/+)$ mice. J Comp Physiol [A] 178:797-802. 